\title{
Evaluation of Total Employment Rate Aged 15-64 in EU15
}

\author{
Joel Chiadikobi Nwaubani, Adanma Ngozi Ohia, Opara Peace, Uzokwe Chinwe Adaugo, \\ Uchechi Mgbafor Ezeji, Christiana Uzoma Ezechukwu
}

\begin{abstract}
Many papers have been written on the subject total employment rate, and most of them stressed on excessive pressure emanating from economic recession, heavy competition, modern and skill biased technological changes as the main principal causes of demands for jobs. Unarguably, evaluating total employment rate remain issues of considerable importance for economists, statisticians, the media and policy makers. However, understanding how the economy works requires a shift from economic modelling to economic analysis. We will consider the use of association model as an alternative to reduced form methods. Against the background of total employment rate, this study considers and estimate the most accurate association model of the Categorical Data Analysis for the total employment rate - employed persons aged 15-64 as a share of the total population of the same age group in the EU15 from 2008-2017. The analysis of association (ANOAS) table is given in order to ascertain the percentage of the data which is covered by each model. We estimate the association model to find the model with the best fit and acceptable. In conclusion we find out that the Column Effects Association Model (C) has the best fit because it covers almost $90 \%$ of the data - giving the best fit among all.
\end{abstract}

Index Terms - EU15, Association models, Log-linear and non-linear models, total employment rate and employed persons aged 15-64.

\section{INTRODUCTION}

Statistically, the employment rate for a given age group is measured as the number of employed people of a given age as a percentage of the total number of people in that same age group. Employed people are defined as those aged 15 and over who report that they have worked in gainful employment for at least one hour in the previous week or who had a job but were absent from work during the reference week while having a formal job attachment.

Employment rates are shown for three age groups: people aged 15 to 24 (those just entering the labour market following education); people aged 25 to 54 (those in their prime working lives); people aged 55 to 64 (those passing the peak of their career and approaching retirement). This

Published on September 10, 2020.

Joel Chiadikobi Nwaubani, Advance Higher Education London, UK.

(corresponding e-mail: joelinocool@yahoo.com)

Adanma Ngozi Ohia, University of Portharcourt, Nigeria.

Opara Peace, Abia Secondary Education Management Board (SEMB), Nigeria.

Uzokwe Chinwe Adaugo, Michael Okpara University of Agriculture Umudike, Nigeria.

Uchechi Mgbafor Ezeji, Amuzukwu Girls’ Secondary School, Nigeria.

Christiana Uzoma Ezechukwu, Agricultural Development Programme (ADP), Nigeria. indicator is seasonally adjusted, and it is measured as a percentage in same age group. To determine the percentage in the labour force we divide the number of people in the labour force by the total adult (working-age) population and multiply by 100 to obtain the percentage. Retirees are counted in the real unemployment rate. The other group that isn't included in the labour force comprises students, homemakers, retired people, and those under 16 who are working, and they are counted in the population.

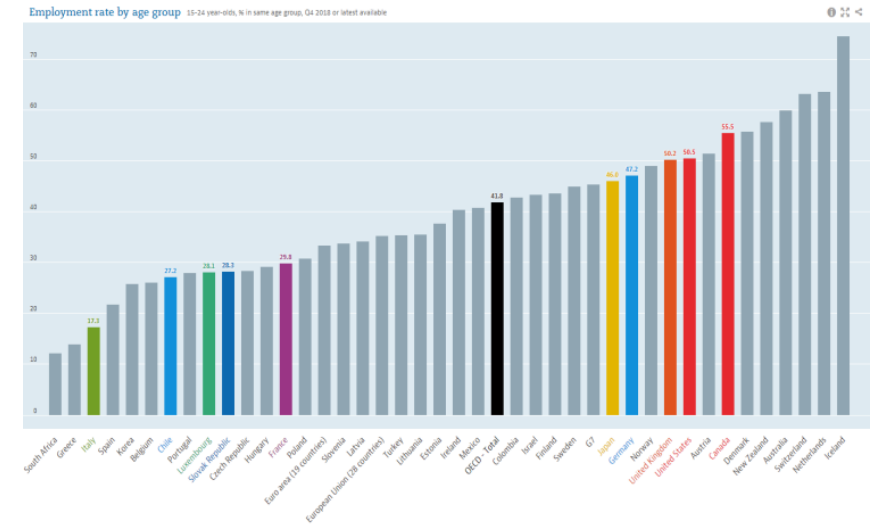

Fig.1. Employment rates are shown for three age groups: people aged 15 to 24 [1].

The EU17 consists of Belgium, Germany, Estonia, Ireland, Greece, Spain, France, Italy, Cyprus, Luxembourg, Malta, the Netherlands, Austria, Portugal, Slovenia, Slovakia and Finland, while the EU28 includes Belgium, Bulgaria, the Czech Republic, Denmark, Germany, Estonia, Ireland, Greece, Spain, France, Italy, Cyprus, Latvia, Lithuania, Luxembourg, Hungary, Croatia, Malta, the Netherlands, Austria, Poland, Portugal, Romania, Slovenia, Slovakia, Finland, Sweden and the United Kingdom.

\section{A. Economic Performance}

According to estimates by Swiss institutions, the EU maintains $30 \%$ of the world's net wealth (estimated at $\$ 223$ trillion in 2015). According to the annual list of the Fortune business magazine, about 161 out of 500 largest businesses in the world have their headquarters within the EU. The average per capita income shows very large deviations across the EU. The richest inhabitants based on the average annual per capita income are located in the center of London (78,000 € / inhabitant), Luxembourg $(62,500 € /$ inhabitant $)$ and Brussels $(52,500 € /$ inhabitant) while the poorest in the northeastern provinces of Romania $(6,900 € /$ inhabitant $)$ and in the southern provinces of Bulgaria $(6,900-7,200 € /$ inhabitant) [2].

Economic performance varies from state to state. The 
Stability and Growth Agreement defines the fiscal criteria for maintaining stability and (economic) convergence. It will be implemented in all Member States, with specific rules applying to the Eurozone area, which stipulate that each Member states should not exceed the deficit of $3 \%$ of GDP and the government debt should not exceed $60 \%$ of GDP. However, many larger members have consistently run deficits significantly above $3 \%$, and the Eurozone area as a whole has a debt ratio of over $60 \%$.From a macroeconomic perspective, the difference between rich nations and developing nations may be summarized by saying that rich nations have at some point in their history experienced extended periods of rapid growth but that the poorer nations either have never experienced sustainable growth or have had periods of short growth, offset by periods of economic decline.

A nation's economic performance depends on many factors, including its natural and human resources, its capital stock (buildings and machines), its technology and the economic choices made by its citizens, both individually and collectively. Another extremely important factor affecting economic performance is the set of macroeconomic policies pursued by the government [3].

\section{STATISTICAL DATA AND PROCESSING OF THE RESULTS}

The data used for this study was obtained from the Organization for Economic Co-operation and Development (OECD), and the Eurostat, calculated on an annual basis. The introduction and processing of observations (data) consists of the total employment rate - employed persons aged 15-64 as a share of the total population of the same age group in the EU15 from 2008 - 2017.

TABLE 1: SHOWING TOTAL EMPLOYMENT RATE - EMPLOYED PERSONS AGED 15-64 AS A SHARE OF THE TOTAL POPULATION OF THE SAME AGE GROUP IN EU15 [4]

\begin{tabular}{|c|c|c|c|c|c|c|c|c|}
\hline TimelGeo & Belgium & Denmark & Germany & Greece & Spain & France & \multirow{2}{*}{ Ireland } & Italy \\
\hline 2008 & 55.7 & 72.3 & 64.7 & 54.2 & 46.1 & 59.1 & 53.0 & 51.4 \\
\hline 2009 & 56.1 & 73.4 & 64.6 & 54.7 & 46.9 & 59.5 & 54.4 & 51.0 \\
\hline 2010 & 56.2 & 73.8 & 64.1 & 55.0 & 47.9 & 59.5 & 55.4 & 51.2 \\
\hline 2011 & 56.8 & 74.9 & 63.7 & 55.1 & 49.4 & 59.6 & 57.6 & 51.3 \\
\hline 2012 & 57.4 & 75.1 & 63.9 & 55.5 & 51.2 & 60.2 & 60.6 & 52.0 \\
\hline 2013 & 59.3 & 76.0 & 65.2 & 55.3 & 53.7 & 60.9 & 63.3 & 52.7 \\
\hline 2014 & 60.5 & 76.3 & 65.6 & 55.7 & 56.2 & 62.1 & 65.2 & 53.7 \\
\hline 2015 & 59.9 & 76.2 & 65.8 & 55.4 & 57.7 & 62.8 & 65.8 & 54.8 \\
\hline 2016 & 59.9 & 75.9 & 65.4 & 56.1 & 58.4 & 63.0 & 65.6 & 55.5 \\
\hline 2017 & 59.6 & 75.1 & 65.1 & 57.8 & 59.7 & 63.2 & 65.4 & 56.1 \\
\hline
\end{tabular}

\begin{tabular}{|c|c|c|c|c|c|c|c|}
\hline TimelGeo & Luxembourg & Netherlands & Austria & Portugal & Finland & Sweden & United Kingdom \\
\hline 2008 & 59.9 & 64.0 & 68.5 & 64.1 & 60.3 & 70.2 & 67.9 \\
\hline 2009 & 58.7 & 64.7 & 68.8 & 63.7 & 61.6 & 70.9 & 68.5 \\
\hline 2010 & 59.2 & 66.3 & 67.8 & 64.1 & 62.4 & 70.3 & 69.0 \\
\hline 2011 & 59.9 & 68.5 & 67.8 & 65.7 & 63.3 & 69.5 & 69.9 \\
\hline 2012 & 60.5 & 70.2 & 67.9 & 66.8 & 64.6 & 70.3 & 70.5 \\
\hline 2013 & 61.7 & 71.7 & 68.6 & 67.4 & 66.4 & 71.7 & 71.0 \\
\hline 2014 & 62.7 & 72.9 & 68.5 & 68.4 & 67.2 & 73.0 & 71.5 \\
\hline 2015 & 63.1 & 74.1 & 68.5 & 69.0 & 68.1 & 74.0 & 71.7 \\
\hline 2016 & 63.4 & 74.4 & 68.7 & 68.8 & 68.1 & 73.6 & 71.7 \\
\hline 2017 & 62.7 & 73.5 & 69.0 & 68.1 & 67.7 & 72.9 & 71.8 \\
\hline
\end{tabular}

With the help of the Categorical Data Analysis program (CDAS), we were able to ascertain the results of our data for the total employment rate - employed persons aged 15-64 as a share of the total population of the same age group in the EU15 from 2006-2015. Below are the values (prices) of all models to be estimated. The statistics used to compare the correlation (association) of the various models are $\mathrm{X}^{2}$ (Pearson) Chi-Square and the Likelihood-Ratio Chi - Square $\mathrm{G}^{2}$-probability ratio [5]. In continuation, the program gives us the following results in Table 2 below.

TABLE 2: THE RESULTS OF THE DATA

\begin{tabular}{|c|c|c|c|c|c|}
\hline Models & $\begin{array}{c}\mathrm{X}^{2} \\
\text { (Pearson)Chi- } \\
\text { Square }\end{array}$ & $\begin{array}{c}\text { Likelihood- } \\
\text { Ratio Chi- } \\
\text { Square G }\end{array}$ & $\begin{array}{c}\text { Degreesof } \\
\text { Freedom }\end{array}$ & $\begin{array}{c}\text { Index of } \\
\text { Dissimilarity }\end{array}$ & $\begin{array}{c}\text { Maximum } \\
\text { Deviation }\end{array}$ \\
\hline $\mathrm{O}$ & 5.90022 & 5.91215 & 126 & 0.00883 & 0.00000000 \\
\hline $\mathrm{U}$ & 5.89269 & 5.90487 & 125 & 0.00886 & 0.00002232 \\
\hline $\mathrm{R}$ & 5.88189 & 5.89438 & 117 & 0.00881 & 0.00001202 \\
\hline $\mathrm{C}$ & 0.80160 & 0.80136 & 112 & 0.00351 & 0.00012508 \\
\hline $\mathrm{R}+\mathrm{C}$ & 0.79111 & 0.79098 & 104 & 0.00350 & 0.00013441 \\
\hline $\mathrm{RC}$ & 0.58943 & 0.58914 & 104 & 0.00306 & 0.00098946 \\
\hline
\end{tabular}




\section{A. Association Model}

In the categorical data analysis system, we apply the methodology by considering six of the most used association models. These are:

1) The model of Independence or null association model which is also symbolized by $(\mathrm{O})$ and holds that there is no relationship between the variables. The log-linear model is:

$$
\log \left(F_{i j}\right)=\lambda+\lambda_{A(i)}+\lambda_{B(j)}
$$

where $\log$ denotes the natural logarithm, $\mathrm{F}_{\mathrm{ij}}$ the expected frequencies under the independence model, $\lambda_{\mathrm{A}(\mathrm{i})}$ are the rows main effects and $\lambda_{\mathrm{B}(\mathrm{j})}$ are the columns main effects [6].

2) The Uniform association model, which is symbolized by (U) in log-linear form is:

$$
\log \left(F_{i j}\right)=\lambda+\lambda_{A(i)}+\lambda_{B(j)}+\varphi \chi_{i} y_{j}
$$

where $\varphi$ is a single parameter for interaction and $\chi_{\mathrm{i}}, \mathrm{y}_{\mathrm{j}}$ are the scores for the row and column variables $(i=1, \ldots, I, j$ $=1, \ldots, \mathrm{J})$ respectively.

3) The row effects model (R) where linear-by-linear interaction holds that

$$
\log \left(F_{i j}\right)=\lambda+\lambda_{A(i)}+\lambda_{B(j)}+\varphi \mu_{I} y_{j}[7]
$$

Where $y_{j}$ are fixed scores for the column variable $(j=1, \ldots$, $\mathrm{J})$ and $\mu_{\mathrm{I}}$ are unknown scores for the row variable (i $=1, \ldots, \mathrm{I})$.

4)The column effects model (C) is the same as the $\mathrm{R}$ model with a change in subscripts:

$$
\log \left(F_{i j}\right)=\lambda+\lambda_{A(i)}+\lambda_{B(j)}+\varphi v_{j} x_{I}
$$

where $\mathrm{x}_{\mathrm{I}}$ are fixed scores for the row variable $(\mathrm{i}=1, \ldots, \mathrm{I})$ and $v_{\mathrm{j}}$ are unknown scores for the column variable $(\mathrm{j}=1, \ldots, \mathrm{J})$.

4) The model that allows both row and column effects in additive form is called the $\mathrm{R}+\mathrm{C}$ model [8]. The logfrequency version of the above model is:

$$
\log \left(F_{i j}\right)=\lambda+\lambda_{A(i)}+\lambda_{B(j)}+\sum_{k=1}^{I-1} \beta_{k} y_{j} Z_{A(k)}+\sum_{k=1}^{J-1} y_{k} x_{j} Z_{B(k)},
$$

where $\chi_{\mathrm{i}}, \mathrm{y}_{\mathrm{j}}$ are the scores (as defined earlier), and $Z_{A(i)}, Z_{B(j)}$ denote to variables (dummy variables) for the row and column levels respectively.

5) The model, instead of additive row and column effects on the local odds ratios, has multiplicative effects called the $\mathrm{R} * \mathrm{C}$ model or model II [9]. The log-multiplicative model is:

$$
\log \left(F_{i j}\right)=\lambda+\lambda_{A(i)}+\lambda_{B(j)}+\varphi \mu_{I} v_{j}
$$

where the row score parameters $\mu_{\mathrm{I}}$ and column score parameters $v_{\mathrm{j}}$ are not known but are estimated in the data.

We aim at finding out the model that has the best fit among the 6 models which we are examining, i.e., total employment rate - employed persons aged 15-64 as a share of the total population of the same age group in the EU15 from 2008-2017. For this reason, first, we are going to examine the Index of Dissimilarity (L2), which shows that, the lesser the number, the more our model will give the best fit to match the data under consideration.

We analyze the six association model describe above, with the help of the categorical data analysis statistical program [10]. We used the Pearson chi-squared $\left(\mathrm{X}^{2}\right)$ statistics, the likelihood-ratio chi-square $\left(\mathrm{G}^{2}\right)$ statistics and the index of dissimilarity which is equated by:

$D=\sum_{I_{j}} \frac{\left|\frac{f_{i j}}{n}-\frac{F_{i j}}{n}\right|}{2}$

Where:

$f_{i j}$ are the observed frequencies,

$F_{i j}$ are the expected frequencies (under the model).

Additionally, we have the following results as shown in the table below:

TABLE 3: INDEX OF DISSIMILARITY

\begin{tabular}{|l|c|}
\hline \multicolumn{1}{|c|}{ Model } & Index of Dissimilarity (D) \\
\hline 1. Null Association-Independence Model(O) & 0.00883 \\
\hline 2.Uniform Association Model (U) & 0.00886 \\
\hline 3. Row-Effects Association Model (R) & 0.00881 \\
\hline 4. Column-Effects Association Model (C) & 0.00351 \\
\hline $\begin{array}{l}\text { 5.Row+Columns Effects Association Mode } \\
(\mathrm{R}+\mathrm{C})\end{array}$ & 0.00350 \\
\hline $\begin{array}{l}\text { 6. Row Column Effects Association Model } \\
(\mathrm{R} * \mathrm{C})\end{array}$ & 0.00306 \\
\hline
\end{tabular}

In Table 3 above, it seems at first sight that the Row Column Effects of the Association Model $(\mathrm{R} * \mathrm{C})$ adjusted better to the percentage of the total employment rate employed persons aged 15-64 as a share of the total population of the same age group in the EU15 from 20062015 for the years under study (having the lowest index of dissimilarity) with $\mathrm{D}=0.00306$.

Since we have models with similar lower ratio, we justify the model with the best fit to match both counties and years by calculating the Index BIC (Bayesian information criterion). In statistics, the Bayesian information criterion (BIC) or Schwarz criterion is a criterion for model selection among a finite set of models; the model with the lowest BIC is preferred. It is based, in part, on the likelihood function. When fitting models, it is possible to increase the likelihood by adding parameters but doing so may result in over-fitting. BIC attempt to resolve this problem by introducing a penalty term for the number of parameters in the model and gives the best solution [11].

The formula for this calculation is:

$$
B I C=G^{2}-(D . F .) \log (n)
$$

Notations:

$\mathrm{G}^{2}=$ the likelihood-ratio chi-square statistics.

d.f. $=$ degrees of freedom of the models.

$\mathrm{n}=$ the size of the sample (9538.9).

$\log (n)=\log (93199028)=9.16313$.

When comparing a number of models, the model with the smallest index of BIC is assumed to be the best. So, we choose the models that have similar and lowest INDEX OF DISSIMILARITY out of the six models. More precisely, we 
will consider the $4^{\text {th }}, 5^{\text {th }}$ and $6^{\text {th }}$ models subsequently.

Subsequently, the calculation is as follows:

$4^{\text {th }}$ model: $\mathrm{BIC}=\mathrm{G}^{2}-$ (d.f) $\log (\mathrm{n})=0.80136-(112 *$

9.16313) $=-1025.4692$

$5^{\text {th }}$ model: $\mathrm{BIC}=\mathrm{G}^{2}-($ d.f $) \log (\mathrm{n})=0.79098-(104 *$

9.16313) $=-952.17454$

$6^{\text {th }}$ model: $\mathrm{BIC}=\mathrm{G}^{2}-$ (d.f) $\log (\mathrm{n})=0.58914-(104 *$

9.16313) $=-952.37638$

As we can see from the above calculations, the 4th model (Column-Effects Association Model (C) finally accounts for the best fit from the results since it has the smallest index of BIC.

\section{B. Analysis of Association Model}

In continuation, the association model passes through several tests to ascertain the accuracy, quality, or satisfactory fit of each model. Tests are done through the use of the likelihood-ratio chi-square $\left(\mathrm{G}^{2}\right)$ statistics and the Pearson chi-squared (X2) distribution. In the case of the $\mathrm{X}^{2}$ distribution, the Statgraph programme will be of good help.

Initially, we observe that the likelihood-ratio chi-square statistic for the Independence model (O) which is $\mathrm{G}^{2}=5.91215$ with 126 degrees of freedom. The 95\% reference point chi-square distribution is 153.382 . It has acceptable fit because the $\mathrm{X}^{2}$ distribution is much greater than the likelihood-ratio chi-square statistic $\mathrm{G}^{2}$.

Subsequently, the Uniform association model has $\mathrm{G}^{2}=5.90487$ with 125 degrees of freedom. The 95\% reference point chi-square distribution is 152.274. As it could be noticed, this statistic is accepted and has a satisfactory fit since the $\mathrm{X}^{2}$ distribution is much larger than the likelihood-ratio chi-square statistic $\mathrm{G}^{2}$.

Moreover, the statistic $\mathrm{G}^{2}$ for the Row model (R) is dramatically increased for 5.89438 with 117 degrees of freedom. The 95\% reference point chi-square distribution is 143.483. The row model is also accepted because the $\mathrm{X}^{2}$ distribution is much greater than the likelihood-ratio chisquare statistic $\mathrm{G}^{2}$

The Column model (C) has $\mathrm{G}^{2}=0.80136$ with 112 degrees of freedom. The $95 \%$ reference point chi-square distribution is 137.914 which show even a much better fit as we can observe that the $\mathrm{X}^{2}$ distribution is very much bigger than the likelihood-ratio chi-square statistic $\mathrm{G}^{2}$.

The statistics of the model $\mathrm{R}+\mathrm{C}$, that takes into account the effects for both Countries and Years in additive form, is $\mathrm{G}^{2}=0.79098$ with 104 degrees of freedom. The $95 \%$ reference point chi-square distribution is 128.98 and has also an acceptable fit since the $\mathrm{X}^{2}$ distribution is greater than the likelihood-ratio chi-square statistic $\mathrm{G}^{2}$.

Finally, the model RC, that is $\log$ multiplicative but not $\log$-linear, the $\mathrm{G}^{2}$ Statistics is 0.58914 with 104 degrees of freedom. The $95 \%$ reference point chi-square distribution is 128.98. Furthermore, the statistics is dramatically increased just as the previous model and they have identical degrees of freedom. Also, this model has an acceptable fit because the $\mathrm{X}^{2}$ distribution is very much larger than the likelihood-ratio chi-square statistic $\mathrm{G}^{2}$.

By virtue of the index of dissimilarity of the models, the model $\mathrm{R}+\mathrm{C}$ and $\mathrm{RC}$ has the best fit. However, we have to find out the degree or level of effects on each model. To verify this, we have to construct the Analysis of association (ANOAS) table.

\section{Analysis of Association Table (ANOAS)}

The ANOAS table in table 4 below was given by [12]. In Table 4 below, the $\mathrm{X}^{2}$ is divided so that it can be used as two factor analysis of variance by making use of the $\mathrm{G}^{2}(0)$ statistics for the base (zero) independence model which measures the total deviation of the variables. In other words, we can find the percentage of the baseline chi-squared $\mathrm{X}^{2}$ distribution, which have effects on each of our models on the phenomenon being studied.

\begin{tabular}{|c|c|c|c|}
\hline \multicolumn{4}{|c|}{ TABLE 4: ANOAS } \\
\hline Models & Likelihood-G ${ }^{2}$ & $\begin{array}{c}\text { Degrees of } \\
\text { Freedom }\end{array}$ & $\begin{array}{c}\text { Index of } \\
\text { Dissimilarity }\end{array}$ \\
\hline $\mathrm{O}$ & 5.91215 & 126 & 0.00883 \\
\hline $\mathrm{U}$ & 5.90487 & 125 & 0.00886 \\
\hline $\mathrm{R}$ & 5.89438 & 117 & 0.00881 \\
\hline $\mathrm{C}$ & 0.80136 & 112 & 0.00351 \\
\hline $\mathrm{R}+\mathrm{C}$ & 0.79098 & 104 & 0.00350 \\
\hline $\mathrm{RC}$ & 0.58914 & 104 & 0.00306 \\
\hline
\end{tabular}

The analysis of association table (ANOAS) has the following differences of our models: $\mathrm{O}-\mathrm{U}$ is the overall or total effects of the models, U-C are the column effects model, C-CR are the column effects model which gives the effects of the column RC and the residuals of the models.

TABLE 5: ANOAS MODEL UNIFORMITY

\begin{tabular}{|l|c|c|c|}
\hline Effects Models & $\mathrm{G}^{2}$ values & D.F. & Percentage \\
\hline 1.General (O-U) & 0.00728 & 1 & $0.12 \%$ \\
\hline 2. Rows(U-C) & 5.10351 & 13 & $86.42 \%$ \\
\hline $\begin{array}{l}\text { 3. Column-effects which gives the } \\
\text { Row-effects (C-RC) }\end{array}$ & 0.21222 & 8 & $3.58 \%$ \\
\hline 4. Residual (RC) & 0.58917 & 104 & $9.96 \%$ \\
\hline Total (O) & 5.91215 & 126 & $\approx 100.00 \%$ \\
\hline
\end{tabular}

From the ANOAS table we created, the uniform association model $(\mathrm{U})$ as shown in table 5 above, covers only $0.12 \%$ of the total baseline chi-squared $\mathrm{X}^{2}$ distribution, the Row model (R) accounts for a large percentage of $86.42 \%$, the Column-effects which gives the Row-effects (C-RC) covers a small percentage of $3.58 \%$ of the baseline chi-squared value. Finally, the row column effects (Residuals) are weaker because the RC model accounts for only $9.96 \%$ of the baseline chi-squared value.

We could therefore observe that at the rate of $9.96 \%$, the variation which is attributed to the null-independence has been measured from the model of RC. This rate is quite unsatisfactory and we can say that the corresponding percentage of the total employment rate - employed persons aged 15-64 as a share of the total population of the same age group in Belgium, Denmark, Germany, Ireland, Greece, Spain, France, Italy, Luxembourg, Netherlands, Austria, Portugal, Finland, Sweden and United Kingdom, as seen from the data taken from the Eurostat, depended slightly negative on the association of both the countries and also from the years under our study (2008-2017).

We could as well say that the percentage of (5.91215$0.58914) / 5.91215=0.90 \%$ of the data is explained by the column effects model (on the local odds ratios in a multiplicative way), thus, giving it a satisfactory fit and acceptable due to better adjustment as was found earlier in 
our study, i.e. the value of the Pearson chi-squared $\mathrm{X}^{2}$ distribution for the $95 \%$ reference point are much larger for the model (RC).

\section{Evaluation Of The Models}

TABLE 6. EVALUATION OF THE BEST MODEL - COLUMN-EFFECTS MODEL (C)

\begin{tabular}{|c|c|c|c|c|}
\hline Years & Countries & Data & $\begin{array}{l}\text { Values of } 0 \\
\text { Model }\left(\mathrm{f}_{\mathrm{ij}}{ }^{1}\right)\end{array}$ & $\begin{array}{c}\text { Values of RC (C) } \\
\text { Model }\left(\mathrm{F}_{\mathrm{ij}}{ }^{2}\right) \\
\end{array}$ \\
\hline ROW & COLUMN & DATA & OBSERVED & EXPECTED \\
\hline 1 & 1 & 55.7000 & 55.5502 & 55.7558 \\
\hline 1 & 2 & 72.3000 & 71.5637 & 73.4485 \\
\hline 1 & 3 & 64.7000 & 61.9231 & 64.2882 \\
\hline 1 & 4 & 54.2000 & 53.0660 & 54.3107 \\
\hline 1 & 5 & 46.1000 & 50.3716 & 45.6233 \\
\hline 1 & 6 & 59.1000 & 58.2733 & 58.8010 \\
\hline 1 & 7 & 53.0000 & 57.9293 & 53.6982 \\
\hline 1 & 8 & 51.4000 & 50.6105 & 50.4038 \\
\hline 1 & 9 & 59.9000 & 58.4548 & 58.9619 \\
\hline 1 & 10 & 64.0000 & 66.9106 & 64.6531 \\
\hline 1 & 11 & 68.5000 & 65.3628 & 68.2951 \\
\hline 1 & 12 & 64.1000 & 63.6429 & 63.9286 \\
\hline 1 & 13 & 60.3000 & 62.0760 & 60.9800 \\
\hline 1 & 14 & 70.2000 & 68.4489 & 69.8087 \\
\hline 1 & 15 & 67.9000 & 67.2163 & 68.4432 \\
\hline 2 & 1 & 56.1000 & 55.9220 & 56.0934 \\
\hline 2 & 2 & 73.4000 & 72.0426 & 73.5327 \\
\hline 2 & 3 & 64.6000 & 62.3376 & 64.1989 \\
\hline 2 & 4 & 54.7000 & 53.4212 & 54.4067 \\
\hline 2 & 5 & 46.9000 & 50.7088 & 46.9201 \\
\hline 2 & 6 & 59.5000 & 58.6633 & 59.0883 \\
\hline 2 & 7 & 54.4000 & 58.3170 & 54.9553 \\
\hline 2 & 8 & 51.0000 & 50.9492 & 50.7951 \\
\hline 2 & 9 & 58.7000 & 58.8460 & 59.2549 \\
\hline 2 & 10 & 64.7000 & 67.3584 & 65.5827 \\
\hline 2 & 11 & 68.8000 & 65.8002 & 68.1036 \\
\hline 2 & 12 & 63.7000 & 64.0689 & 64.3047 \\
\hline 2 & 13 & 61.6000 & 62.4915 & 61.6368 \\
\hline 2 & 14 & 70.9000 & 68.9070 & 69.9860 \\
\hline 2 & 15 & 68.5000 & 67.6662 & 68.6410 \\
\hline 3 & 1 & 56.2000 & 56.2085 & 56.3415 \\
\hline 3 & 2 & 73.8000 & 72.4117 & 73.4975 \\
\hline 3 & 3 & 64.1000 & 62.6569 & 64.0057 \\
\hline 3 & 4 & 55.0000 & 53.6949 & 54.4143 \\
\hline 3 & 5 & 47.9000 & 50.9685 & 48.1754 \\
\hline 3 & 6 & 59.5000 & 58.9638 & 59.2806 \\
\hline 3 & 7 & 55.4000 & 58.6158 & 56.1505 \\
\hline 3 & 8 & 51.2000 & 51.2102 & 51.1065 \\
\hline 3 & 9 & 59.2000 & 59.1475 & 59.4527 \\
\hline 3 & 10 & 66.3000 & 67.7035 & 66.4177 \\
\hline 3 & 11 & 67.8000 & 66.1373 & 67.8024 \\
\hline 3 & 12 & 64.1000 & 64.3971 & 64.5780 \\
\hline 3 & 13 & 62.4000 & 62.8116 & 62.1996 \\
\hline 3 & 14 & 70.3000 & 69.2600 & 70.0500 \\
\hline 3 & 15 & 69.0000 & 68.0128 & 68.7276 \\
\hline 4 & 1 & 56.8000 & 56.8667 & 56.9580 \\
\hline 4 & 2 & 74.9000 & 73.2597 & 73.9393 \\
\hline 4 & 3 & 63.7000 & 63.3907 & 64.2273 \\
\hline 4 & 4 & 55.1000 & 54.3237 & 54.7753 \\
\hline 4 & 5 & 49.4000 & 51.5654 & 49.7854 \\
\hline 4 & 6 & 59.6000 & 59.6543 & 59.8596 \\
\hline 4 & 7 & 57.6000 & 59.3022 & 57.7442 \\
\hline 4 & 8 & 51.3000 & 51.8100 & 51.7535 \\
\hline 4 & 9 & 59.9000 & 59.8402 & 60.0383 \\
\hline 4 & 10 & 68.5000 & 68.4964 & 67.7000 \\
\hline 4 & 11 & 67.8000 & 66.9118 & 67.9407 \\
\hline 4 & 12 & 65.7000 & 65.1513 & 65.2735 \\
\hline 4 & 13 & 63.3000 & 63.5472 & 63.1749 \\
\hline 4 & 14 & 69.5000 & 70.0711 & 70.5691 \\
\hline 4 & 15 & 69.9000 & 68.8093 & 69.2610 \\
\hline 5 & 1 & 57.4000 & 57.7018 & 57.7467 \\
\hline 5 & 2 & 75.1000 & 74.3354 & 74.5974 \\
\hline 5 & 3 & 63.9000 & 64.3215 & 64.6349 \\
\hline 5 & 4 & 55.5000 & 55.1214 & 55.2971 \\
\hline
\end{tabular}

\begin{tabular}{|c|c|c|c|c|}
\hline 5 & 5 & 51.2000 & 52.3226 & 51.5970 \\
\hline 5 & 6 & 60.2000 & 60.5303 & 60.6180 \\
\hline 5 & 7 & 60.6000 & 60.1730 & 59.5537 \\
\hline 5 & 8 & 52.0000 & 52.5707 & 52.5593 \\
\hline 5 & 9 & 60.5000 & 60.7189 & 60.8040 \\
\hline 5 & 10 & 70.2000 & 69.5021 & 69.2053 \\
\hline 5 & 11 & 67.9000 & 67.8944 & 68.2749 \\
\hline 5 & 12 & 66.8000 & 66.1079 & 66.1660 \\
\hline 5 & 13 & 64.6000 & 64.4803 & 64.3499 \\
\hline 5 & 14 & 70.3000 & 71.1000 & 71.2964 \\
\hline 5 & 15 & 70.5000 & 69.8197 & 69.9992 \\
\hline 6 & 1 & 59.3000 & 58.8111 & 58.8046 \\
\hline 6 & 2 & 76.0000 & 75.7645 & 75.5933 \\
\hline 6 & 3 & 65.2000 & 65.5581 & 65.3319 \\
\hline 6 & 4 & 55.3000 & 56.1811 & 56.0700 \\
\hline 6 & 5 & 53.7000 & 53.3285 & 53.7105 \\
\hline 6 & 6 & 60.9000 & 61.6940 & 61.6567 \\
\hline 6 & 7 & 63.3000 & 61.3298 & 61.6908 \\
\hline 6 & 8 & 52.7000 & 53.5814 & 53.6131 \\
\hline 6 & 9 & 61.7000 & 61.8862 & 61.8510 \\
\hline 6 & 10 & 71.7000 & 70.8383 & 71.0561 \\
\hline 6 & 11 & 68.6000 & 69.1996 & 68.9133 \\
\hline 6 & 12 & 67.4000 & 67.3788 & 67.3666 \\
\hline 6 & 13 & 66.4000 & 65.7199 & 65.8359 \\
\hline 6 & 14 & 71.7000 & 72.4669 & 72.3489 \\
\hline 6 & 15 & 71.0000 & 71.1620 & 71.0572 \\
\hline 7 & 1 & 60.5000 & 59.7009 & 59.6374 \\
\hline 7 & 2 & 76.3000 & 76.9109 & 76.2899 \\
\hline 7 & 3 & 65.6000 & 66.5500 & 65.7670 \\
\hline 7 & 4 & 55.7000 & 57.0311 & 56.6217 \\
\hline 7 & 5 & 56.2000 & 54.1354 & 55.6822 \\
\hline 7 & 6 & 62.1000 & 62.6275 & 62.4573 \\
\hline 7 & 7 & 65.2000 & 62.2578 & 63.6438 \\
\hline 7 & 8 & 53.7000 & 54.3921 & 54.4648 \\
\hline 7 & 9 & 62.7000 & 62.8226 & 62.6592 \\
\hline 7 & 10 & 72.9000 & 71.9102 & 72.6586 \\
\hline 7 & 11 & 68.5000 & 70.2467 & 69.2738 \\
\hline 7 & 12 & 68.4000 & 68.3983 & 68.3090 \\
\hline 7 & 13 & 67.2000 & 66.7143 & 67.0812 \\
\hline 7 & 14 & 73.0000 & 73.5634 & 73.1172 \\
\hline 7 & 15 & 71.5000 & 72.2388 & 71.8368 \\
\hline 8 & 1 & 59.9000 & 60.1520 & 60.0267 \\
\hline 8 & 2 & 76.2000 & 77.4920 & 76.4132 \\
\hline 8 & 3 & 65.8000 & 67.0528 & 65.7064 \\
\hline 8 & 4 & 55.4000 & 57.4620 & 56.7483 \\
\hline 8 & 5 & 57.7000 & 54.5444 & 57.2918 \\
\hline 8 & 6 & 62.8000 & 63.1006 & 62.7918 \\
\hline 8 & 7 & 65.8000 & 62.7281 & 65.1643 \\
\hline 8 & 8 & 54.8000 & 54.8031 & 54.9134 \\
\hline 8 & 9 & 63.1000 & 63.2972 & 63.0001 \\
\hline 8 & 10 & 74.1000 & 72.4534 & 73.7379 \\
\hline 8 & 11 & 68.5000 & 70.7774 & 69.1119 \\
\hline 8 & 12 & 69.0000 & 68.9151 & 68.7430 \\
\hline 8 & 13 & 68.1000 & 67.2183 & 67.8356 \\
\hline 8 & 14 & 74.0000 & 74.1192 & 73.3374 \\
\hline 8 & 15 & 71.7000 & 72.7845 & 72.0781 \\
\hline 9 & 1 & 59.9000 & 60.2861 & 60.0951 \\
\hline 9 & 2 & 75.9000 & 77.6647 & 76.1271 \\
\hline 9 & 3 & 65.4000 & 67.2023 & 65.2946 \\
\hline 9 & 4 & 56.7000 & 57.5901 & 56.5708 \\
\hline 9 & 5 & 58.4000 & 54.6660 & 58.6323 \\
\hline 9 & 6 & 63.0000 & 63.2413 & 62.7903 \\
\hline 9 & 7 & 65.6000 & 62.8680 & 66.3639 \\
\hline 9 & 8 & 55.5000 & 54.9252 & 55.0694 \\
\hline 9 & 9 & 63.4000 & 63.4383 & 63.0038 \\
\hline 9 & 10 & 74.4000 & 72.6149 & 74.4327 \\
\hline 9 & 11 & 68.7000 & 70.9352 & 68.5814 \\
\hline 9 & 12 & 68.8000 & 69.0687 & 68.8096 \\
\hline 9 & 13 & 68.1000 & 67.3682 & 68.2312 \\
\hline 9 & 14 & 73.6000 & 74.2844 & 73.1645 \\
\hline 9 & 15 & 71.7000 & 72.9468 & 71.9332 \\
\hline 10 & 1 & 59.6000 & 60.2007 & 59.9408 \\
\hline 10 & 2 & 75.1000 & 77.5548 & 75.5611 \\
\hline 10 & 3 & 65.1000 & 67.1071 & 64.6450 \\
\hline 10 & 4 & 57.8000 & 57.5086 & 56.1850 \\
\hline 10 & 5 & 59.7000 & 54.5886 & 59.7820 \\
\hline
\end{tabular}

Vol 5 | Issue 5 | September 2020 


\begin{tabular}{|l|c|l|l|l|}
\hline 10 & 6 & 63.2000 & 63.1518 & 62.5563 \\
\hline 10 & 7 & 65.4000 & 62.7790 & 67.3354 \\
\hline 10 & 8 & 56.1000 & 54.8475 & 55.0213 \\
\hline 10 & 9 & 62.7000 & 63.3485 & 62.7741 \\
\hline 10 & 10 & 73.5000 & 72.5122 & 74.8557 \\
\hline 10 & 11 & 69.0000 & 70.8347 & 67.8028 \\
\hline 10 & 12 & 68.1000 & 68.9709 & 68.6211 \\
\hline 10 & 13 & 67.7000 & 67.2728 & 68.3749 \\
\hline 10 & 14 & 72.9000 & 74.1792 & 72.7217 \\
\hline 10 & 15 & 71.8000 & 72.8435 & 71.5227 \\
\hline
\end{tabular}

fij: Expected frequencies of the independence model.

2Fij: Expected frequencies of the model C.

From Table 6 above, it could be seen that the prices (value) of the Column-effects model (C) fully fitted to the data.

\section{LOGARITHMS OF THE COLUMN-EFFECTS ASSOCIATION $\operatorname{MODEL}(\mathrm{C})$}

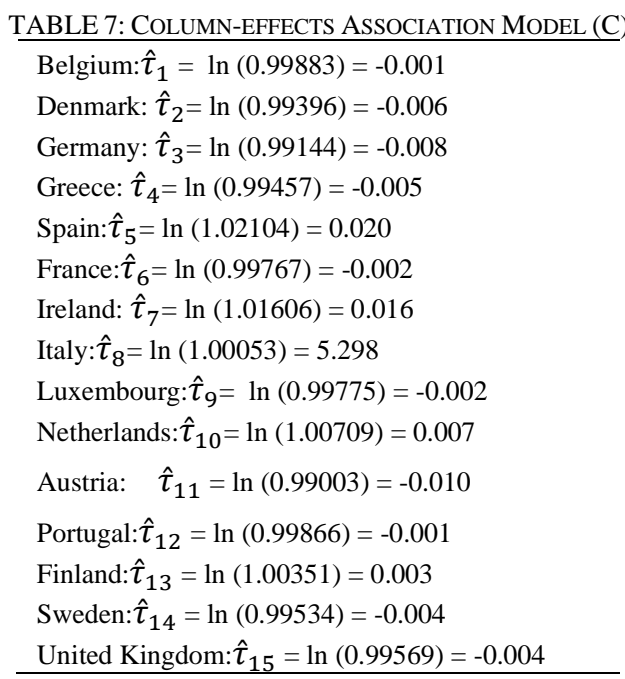

\section{RESEARCH FINDINGS ON TOTAL EMPLOYMENT RATE - EMPLOYED PERSONS AGED 15-64}

Evaluating these 15 countries which formed the EU15 from 1951 to 1995, i.e. Belgium, Germany, France, Italy, Luxemburg, Holland, Denmark, Ireland, United Kingdom, Greece, Spain, Portugal, Austria, Finland, Sweden, our findings shows that the employment rate of the population aged 15-64 rose by 7.2 percentage between 2006 and 2015 . A steady growth was accompanied by in the share of temporary employees, which increased from 2.5 percent to 11.9 percent of total employment. On the other hand, the number of hours actually worked per week drastically decreased in the EU15.

For instance, we compared Italy and Spain, we find out that $\hat{\tau}_{8}-\hat{\tau}_{5}=5.278, \exp (5.278)=1.96$. That is, Italy has 2 percent more workers aged 15-64 than Spain.

In the Scandinavian countries such as Sweden and Finland, the difference between them is $\hat{\tau}_{14}-\hat{\tau}_{13}=-0.007$, $\exp (-0.007)=0.99$. This means that Finland has almost the same percentage of workers aged 15-64 with Sweden.

In the case Greece and Italy $\hat{\tau}_{4}-\hat{\tau}_{8}=-5,303, \exp (-5.303)=$ 0.005 , the difference in the percentage of workers aged 1564 is very minimal, i.e., 0,005 fewer workers in Italy.

Even among the advanced countries of Europe there are variations in the number. More specifically between
Luxembourg and Sweden $\hat{\tau}_{9^{-}} \hat{\tau}_{14}=0.002$, exp $(0.002)=$ 1.00 , we find out that Luxembourg has equal percentage of workers aged 15-64 with Sweden.

Finally, comparing the number of workers aged 15-64 between the United Kingdom and Denmark, we see that $\hat{\tau}_{15^{-}}$ $\hat{\tau}_{2}=0.002, \exp (0.002)=1.00$. It means that the United Kingdom also have equal percentage of workers aged 15-64 with Denmark.

\section{SUMMARY}

The association model has a good fit and acceptable. However, the Column Effects Association Model (C) is much better and fully fitted to the data because it covers pretty well $100 \%$ of the data, thus, giving the best fit among all.

However, to be more precise, the total employment rate employed persons aged 15-64 as a share of the total population of the same age group in the EU15 from 20082017 may have been influenced by various factors; these could be as a result of:

- A nation's natural and human resources, its capital stock (buildings and machines), its technology and the economic choices made by its citizens, both individually and collectively [13].

- Economic labour migration and social development

- The living standard of each country - the degree of utilization of the workforce, which is directly related to efficiency in the productivity of her citizens (the quantity of the goods and services that a worker can produce for each hour of work. A country may prosper if her citizens are productive and do not possess many anti-growth behaviours such as corruption and bad work ethic [14].

- A country's mortality rate; and

- Several other factors that is difficult to be determined in each country.

\section{CONCLUSION}

We should mention that $\Theta$, which is 0.99993 , i.e. approximately equal to 1 , disclose that we have independence between the variables. To determine the degree of association (correlation) between these countries and years, we use the $\theta$ of the second model, (the uniform association model which is represented by (U) for calculation. More specifically, the innate correlation index in log-linear form is equal to:

$$
\log \left(F_{i j}\right)=\lambda+\lambda_{A(i)}+\lambda_{B(j)}+\varphi \chi_{i} y_{j}
$$

where $\varphi$ is a single parameter for interaction [15], [16].

The parameter of interaction

$$
\begin{gathered}
\varphi=\log \theta=\log (0.99993) \\
\Phi=\ln (0.99993)=-7.00024 \\
|\varphi 1 / 2|=\sqrt{ } 7.00024=2.6457966
\end{gathered}
$$




$$
\varphi 1 / 2=\sqrt{ } 7.00024=2.6457966
$$

From our study on the association model for the total employment rate - employed persons aged 15-64, we could therefore, conclude that there is a negative correlation between countries and years in the total employment rate employed persons aged 15-64 as a share of the total population of the same age group in the EU15 from 20082017. It will be interesting to know that experienceweighted measures can account for variation in work characteristics (e.g. working time) and job search behaviour (e.g. duration of unemployment) across countries and years. The definitions of employment are simple and augment the comparability across time and space.

\section{REFERENCES}

[1] OECD Employment rate by age group (indicator / Outlook): Labour market statistics

[2] Nwaubani, J., Tsianta, A., \& Zelka, M. (2019). A Quantitative Research on the Effectiveness of the Implementation of Supply Chain Management, Logistics \& Marketing Function - The Greek Paradigm. EJBMR, European Journal of Business and Management Research. Vol. 4, No. 6, November 2019.

[3] Andrew Abel, Ben Bernanke and Robert McNabb; Macroeconomics ( $5^{\text {th }}$ edition), Pearson Education, Inc., publishing as Pearson Addison Wesley, 2005, p.10.

[4] Eurostat/US: Bureau of Economic Analysis/JP: Labour - Economic and Social Research Institute

[5] Eliason P. Scott \& Clifford Clogg, (1990), Categorical Data Analysis (CDAS) NBER working P., 510.

[6] Diewert, W. Erwin, (1976). Exact and Superlative Index Numbers,', Journal of econometrics May 1976, 4: 115-45.

[7] Goodman, L.A., (1979a). Multiple Models for the Analysis of Occupational Mobility Tables and Other Kinds of CrossClassification Tables. “American Journal of Sociology”, 84:804-819.

[8] Goodman, L.A., (1979b). Multiple Models for the Analysis of Occupational Mobility Tables and Other Kinds of CrossClassification Tables. "American Journal of Sociology".

[9] Goodman, L.A., (1981a). Association models and the Bivariate Normal for Contingency Tables with Ordered Categories. Biometrica, 68:347-55.

[10] Clogg, C.C. (1990), Analysis of Association (ANOAS) Program.

[11] Schwarz, Gideon E. (1978), "Estimating the dimension of a model", Annals of Statistics, 6 (2): 461-464, doi:10.1214/aos/1176344136, MR 0468014.

[12] Goodman, L.A., (1981b). Association Models and Canonical Correlation in the Analysis of Cross-Classifications Having Ordered Categories. "Journal of American Statistical Association", 76:3,2034.

[13] Olson, M. (1982). The Rise and Decline of Nations: Economic Growth, Economic Rigidities and Stagflation, New Haven: Yale University Press.

[14] Fairbanks, Michael. (2005). Changing the Mind of a Nation: Elements in a Process for Creating Prosperity, "in Culture Matters", Huntington, editors, "New York: Basic Books", pp.270-281.

[15] Haritou A., Nwaubani J. C. (2008). "Categorical Data Analysis "Working paper (University Press).

[16] Haritou A., Nwaubani J. C. (2010). "Categorical Data Analysis" (University Press) Working paper. 